\title{
Reactivation of Mature Oilfields: A Multifaceted Production Management
}

\author{
Eduardo Oliveira Teles, Ana Paula Maia Tanajura, Francisco Gaudêncio Mendonça Freires, and \\ Ednildo Andrade Torres
}

\begin{abstract}
The pressure of an increased global energy demand and the increase of oil prices stimulate the reactivation of oil fields that in the past were considered non-profitable. The reactivation of these fields, also known as mature oil fields, carries with it uncertainties regarding production and management. For more than one decade, Brazilian National Agency of Petroleum, Natural Gas and Bio-Fuels (ANP) auction mature oil and gas fields that have been returned by Petrobras, the Brazilian oil company, over the years. This business is not attractive for big oil companies because the recent opportunity to explore pre-salt in Brazil. However, it has rules and aspects that difficult the insertion of small and medium enterprises (SME). This work aims to present how to reactivate mature oilfields through multifaceted aspects of production management. The paper focuses on the methodology of creating facets in the oilfield reactivation process. It comprises the all cycle: bidding, production, and deactivation process of the producing area. From the facet definition and bibliometric analyzes it is possible to define profiles for managers and managing aspects for each subarea of production process. We intend with this proposal to help develop new mechanisms facilitating the insertion of SME in the activities of oil exploration and production.
\end{abstract}

Index Terms-Mature fields, multifaceted management, small and medium companies.

\section{INTRODUCTION}

In recent years, the production of oil and gas in mature fields by companies of different sizes has been realized. There is a tendency to expand the participation of small companies in this market with the reduction in participation of big companies as Petrobras, the national oil company in Brazil. The Brazilian regulatory model tends to be adjusted in order to understand and stimulate this type of operation. It encourage generation of employment and incomes in the regions that are located in these on-shore oilfields.

There many definitions for mature oil fields [1]-[3]. In this paper, we adopt the definition from Câmara: a mature field

Manuscript received February 11, 2015; revised June 21, 2015.

Eduardo Oliveira Teles is with the Program of Industrial Engineer, Federal University of Bahia, Salvador, Bahia, Brazil. He is also with the Department of Informatics, Federal Institute of Education, Science and Technology of Bahia - Camaçari, Bahia, Brazil (e-mail: eoteles@gmail.com).

Ana Paula Maia Tanajura is with the Program of Industrial Engineer, Federal University of Bahia, Salvador, Bahia, Brazil. She is also with the Senai Cimatec, Salvador, Bahia, Brazil (e-mail: anapaula_tanajura@hotmail.com).

Francisco Gaudêncio Mendonça Freires and Ednildo Andrade Torres are with the Program of Industrial Engineer, Federal University of Bahia, Salvador, Bahia, Brazil (e-mail: gaudenciof@yahoo.com, ednildo@ufba.br). produced $40 \%$ of recoverable oil volume, based on initial studies [4]. Mature fields are those in advanced stage of production life cycle and, mostly, require some recovery technique.

After the recent opportunities of investments to explore the area known as Pre-Salt in Brazil, small on-shore fields with low profit is not interesting anymore for large enterprises and public/private consortia. However, there is still difficulty in inserting small companies in this business because the existing rules or the lack of them, and also the reduced number of auctions in recent years by the ANP, Brazilian regulatory agency.

This paper aims to present how the reactivation of wells in a mature field can be done. We propose a methodology with a multifaceted analysis that includes the whole reactivation process: request for proposals, concession of exploration, start-up, production stage and decommissioning. We start with the bibliometric analyzes that defines 5 important facets related to oil and gas exploration (environments, contractual, economic, technical, and decision-making). The paper contribution is the business model that helps the insertion of SMC in oil and gas business. It is an ongoing research in Federal University of Bahia in Brazil that includes the methodology and a hybrid algorithm for decision making in reactivation process, issue that will be detailed in a second paper.

\section{General VIEW - OIL AND GAS LifE CYClE}

The supply chain of oil, in general, can be subdivided into the following stages: production, distribution, refining and retailing [5]. This work takes as reference the life cycle of a mature on-shore oilfield. The life cycle of exploration and production projects has been estimated between 20 and 30 years and has three stages: exploration, development and production [6]. There are different activities in each stage and professionals with different specialties.

In the exploration stage, the goal is the identification of oil or gas reserves. To accomplish this, geological studies are conducted. After confirming the existence of hydrocarbons, the next step begins: the field development. In the development stage, the production is planned and all necessary resources are evaluated. Finally, the production extraction occurs in order to ensure the highest profit. This step also includes the abandonment of the field.

Jean-Pierre Favennec and Nadine Bret-Rouzart summarize the stages of oil and gas new projects [7]: Preliminary studies (initial analyzes of the discovered reserve, with advances in exploratory activities); Conceptual Studie (definition of the 
architecture to the field development, a comparison of technical variables and investment costs); Preliminary design (it contains information of all operations and defines the decision regarding the investment); Basic engineering (selection of service providing companies for construction and assembly); Engineering, supply, procurement and construction (conclusion of the plant construction and final check of the designed and installed items according to the operational requirements of the project); Production startup (the facilities are approved and ready for use); Operation (The beginning of the production cycle).

The oil cycle in Brazil began in the late nineteenth century, when came the first searches for this ore in the Brazilian underground. The first oil field - economically feasible was discovered in 1939, in Lobato municipality, mediations of the Reconcavo Baiano, which was removed oil of good quality and suitable marketing.

The oil has a great relevance to our lives, due to be used as fuel, as well as being added in the manufacture of a multitude of products. Until recently, the Brazil did not have enough oil production to the domestic supply, thus was dependent on imported resource, especially the Middle East, but the country as of 2007 reached self-sufficiency. Currently, the production exceeds 2 million barrels.

For the petroleum products we need to pass it through several stages of processing. After being extracted from underground, it is transported to refineries, which make the processing of raw ore into fuel, raw materials and by-products.

The authors do not explicitly consider the activity of abandonment. But, there are costs associated to this activity that should be considered in the end of the production life cycle. In the sequence, we describe the mature fields in Brazil, fields in an advanced stage of operation.

\section{MATURE FIELDS IN BRAZIL: A REVIEW}

After many years of exploration and production, several Brazilian onshore oilfields reached a level considered economically unfeasible for large companies. For these companies, the daily production of these fields does not generate enough profit. As a result, many of these fields were returned to the ANP, the regulatory agency. ANP made some auctions and tendered those fields. With the call of the Petroleum Law (9478/97) [8], for example, a reduction of the field held by Petrobras under the projects of these fields come to the conclusion and pass these fields to be returned to the regulatory agency.

The law 12351 [9], 2010 was another breakthrough in the sector. It defined that the Executive branch is responsible to stablish policies and measures to increase the participation of small and medium companys in the exploration, development and production of oil and gas activities. This law demonstrates the trend in Brazilian of bidding blocks considered mature and not cost effective.

The first round of bidding of mature field areas occurred in May 2000. 73 areas were offered, but only 13 were acquired because of the various risks regarding the oil production. After the increased on data availability and lower investment, there was a growing interest in exploring these areas by SMEs. One of the steps of the seventh round of ANP bidding occurred only at mature fields whose profile production history was not interesting for big players. The bid success was $94 \%$, which reflects a true niche market with good potential [10], [11].

In the scenario of mature fields - low production, high operational costs and low profit for big players - how it could be a good investment option for SME? After exhausting natural energy reservoirs, various recovery techniques can be applied to increase the productive time of life. Moreover, the decision to drop and return of a field varies according to the methods and technologies used. Additionally, production systems already exist in the reactivation of mature fields. It is the responsibility of the manager to define and manage the revitalization strategy adopted. It follows information about bibliometric study.

\section{BIBLIOMETRIC STUDY}

The bibliometric study uses terms and keywords, authors and indexed publications to generate a structured knowledge in the field of study. One way to structure the bibliometric study is by building a tree of keywords. This technique divides the initial research on different facets, allowing a dual-direction both in terms of coverage of the topic, as the depth of each area/facet [12]. Bibliometric study subsidized the construction of the model presented in this article.

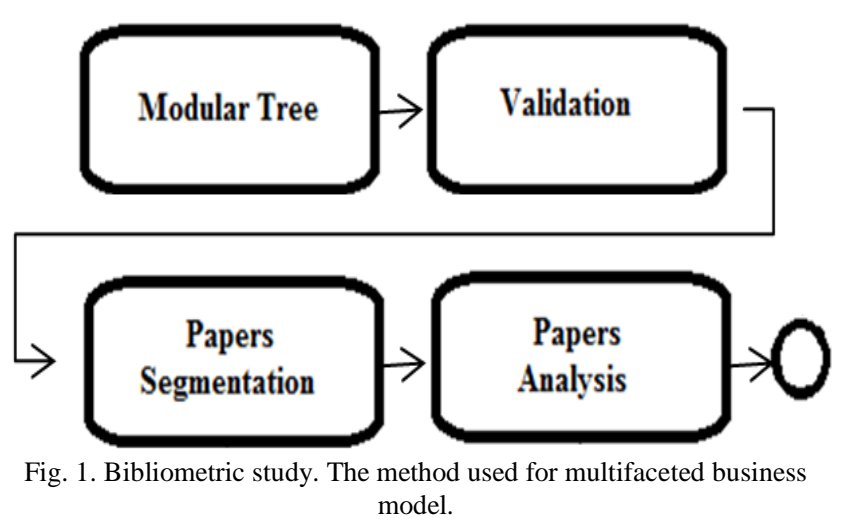

Databases were used to define the relevant terms. The collected material more relevant and highest number of citations by subject area of modular tree serves as a reference for the theoretical background of the research and to assist management in view of the quality and quantity of technical information available. The following will be presented the multifaceted model for production management to reactivate fields and each area will be discussed (see Fig. 1).

\section{THE FACETS OF MATURE OIL FIELdS MANAGEMENT}

The methodology allowed the targeting of research in 5 aspects: environments, contractual, economic, technical, and decision-making. In the vertical direction, the modular tree (Table I) allows the scope of the issue in targeting facets. In the horizontal direction, were selected for deepening terms in each subarea. 
TABLE I: MODULAR TREE

\section{Inicial Objective}

Propose a hybrid algorithm for integrated decision-making process for the reactivation of areas with marginal accumulations of oil and gas.

\section{Facets}

Environment

Contractual

Economic

Technical

Decision-making

Environment Monitoring, rehabilitation area, processing effluents, environmental risks, licensing

Contractual Signing bonuses, royalties, concession regime, auction, minimum local content

Economic

Opex, Capex, IRR, costs, expenses, sensitivity analysis, NPV

Technical

Development, production, injection, pumping, collection, well installation, onshore

Decision

Decision-tree, Real options, Fuzzy, Utility theory, business process management - BPM.

For the reactivation of mature fields is necessary to consider these five facets in each steps of exploration projects. Because of part of the infrastructure already exists, only in a few buildings and units renovation will be made. In such cases, the stage of preliminary design is shorter in duration and the start of production is faster.

In the Fig. 2 shows the order of the management of reactivation by facets. It includes the bidding round, company obligations and action for production start-up. The first part of figure shows the phases of exploration and production. In all these phases, facets presented in the second part of the figure are important. The project evaluation covers the detailed study of all the risks (technical and financial) even in areas of reactivation, where these are relatively low because of the information available on auctions.

The company participates in the auction that has initially access to environmental and contractual aspects. Environmental legislation and environmental requirements vary with each state in Brazil. In areas that were already producing, new businesses can use previous reports. For contractual requirements, a legal, contractual and tax knowledge is required. The technical and economic factors are the greatest interest. Technical decisions influence directly the cost of production, the productive life cycle and return on investment.

The economic analysis or risk analysis should consider the risk of commerciality, when a new field is discovered noncommercial [13]. Despite the risk analysis is a technique commonly applied to large businesses, where a team of strategic planning decides on drilling, it can also be applied by SMEs Production management in the field should have a multidisciplinary profile for the integrated management of assets. Skills in environmental, contractual, technical and financial allow minimizing business risks.

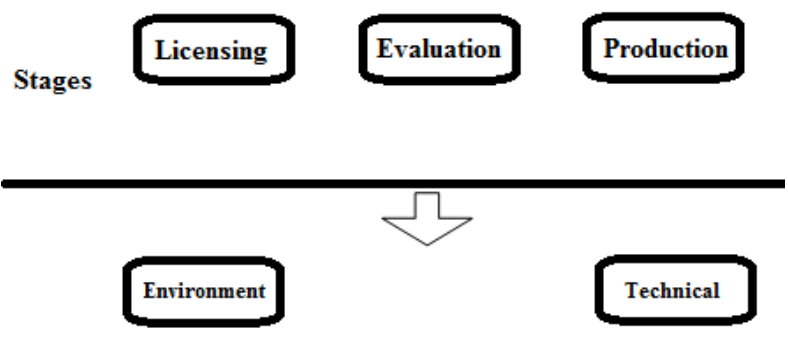

Facets
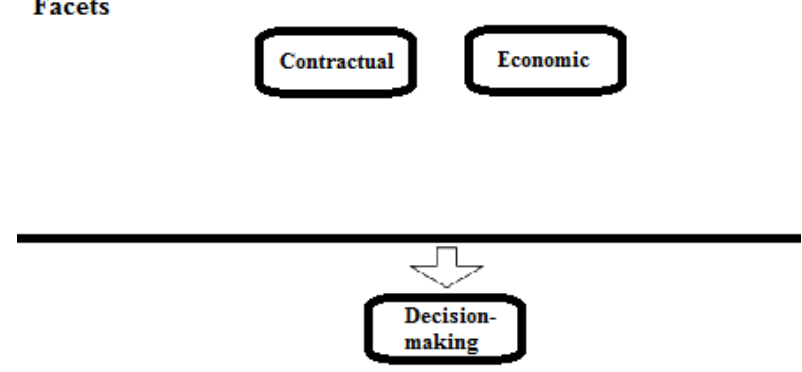

Fig. 2. Facets - modular tree.

The last facet, decision making, is the most important because it gathers all the others. There are decisions during the entire life cycle of an oil field, from deciding to participate in the auction, until the decision of closure. During the operation phase, the company evaluates the level of production and decides for continuity of operations. At the end of this period, managers, with their multidisciplinary profiles, can assess the feasibility of whether to continue the activities referring to the contracted period.

\section{CONCLUSION}

There is an investment opportunity. Many oilfields considered economically marginal were returned to large companies. But these fields can be economically viable for small and medium businesses. In addition, Law 12.351 initiates the review of public policies on taxation and supervision to facilitate the exploitation of mature fields. Despite high investments, the risks are getting smaller. Reactivation of mature oil wells requires a multifaceted production management.

This work demonstrated how the facets of management were defined from the bibliometric analysis. Environmental, contractual, technical and economic aspects, when considered by specialist managers in each area, support the decisions correctly, especially for SMEs.

\section{ACKNOWLEDGMENT}

Authors thank sponsor and financial support of: SENAI Cimatec and PRPGI - IFBA (Edital Inovação 007/2014).

\section{REFERENCES}

[1] C. Cheatwood and A. E. Guzman, "Comparison of reservoir Properties and development history: Spraberry trend field, west Texas and 
Chincontepec field," presented at the SPE International Petroleum Conference and Exhibition on Mexico, Vilahermosa, Mexico, 2002.

[2] W. W. Fleckenstan, "Redevelopment activities in the Carpentaria field off shore Santa Barbara Country, California: Slimhole horizontals reap big beneficits," presented at the SPE/AAPG Western Regional Meeting, Long Beach, California, 2000.

[3] P. K. Ponde and M. B. Clark, "Data acquisition design and implementation opportunities and challenges for effective programs in mature reservoirs," presented at the SPE/DE Ninth Symposium on Improved Oil Recovery, Tulsa, Oklahoma, EUA, 1999.

[4] R. J. B. Câmara, "Mature fields and marginal fields - Settings for regulatory effects," Ms dissertation, Universidade de Salvador UNIFACS, Departamento de Engenharia e Arquitetura, Mestrado em Regulação da Indústria de Energia, Salvador, Brazil, p. 120, 2004

[5] C. M. Chima, "Supply-chain management issues in the oil and gas industry," Journal of Business \& Economics Research. vol. 5, no. 6, pp. $1-30,2007$.

[6] C. M. C. Jacinto, "Acoplamento, simulação e otimização de estratégias de desenvolvimento de campos de petróleo e gás sob incerteza, com aplicações na construção de poços e campos inteligentes," $\mathrm{PhD}$ thesis, Programa de Engenharia Civil, Rio de Janeiro, p. 136, 2009.

[7] J. Favennec and N. Bret-Rouzant, Petróleo e Gás Natural: Como Produzir e a que Custo, 2nd ed., Rio de Janeiro, 2011.

[8] Brazil. Lei 9.478 de 06 de agosto de 1997, 1997.

[9] Brazil. Lei 12.351 de 22 de dezembro de 2010, 2010.

[10] G. M. Braga, "Bibliometric relations between the front search and reviews literature: Applied study of information science," Ms dissertation, Postgraduate Course in Information Science, Rio de Janeiro, p. 162, 1972.

[11] ANP. (2007). Brasil-rounds Licitações de Petróleo e Gás. [Online]. Available: http://www.brasil-rounds.gov.br

[12] J. R. F. Filho, Ensaio Teórico Pesquisa Bibliográfica em Estratégia de Operações, Apostila do Programa de Pós-Graduação em Engenharia de Produção, Niterói, 2009.

[13] S. Amuí, Petróleo e Gás Natural Para Executivos: Exploração de Áreas, Perfuração e Completação de poços e Produção de Hidrocarbonetos, Rio de Janeiro, Interciência, 2010.

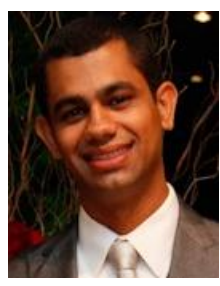

Eduardo Oliveira Teles is a $\mathrm{PhD}$ student with the Industrial Engineering Program, Federal University of Bahia. He is currently a professor at Federal Institute of Education, Science and Technology of Bahia.

He works with modeling and development of decision support tools for the industry, robotics and virtual learning environments. His research topics are: 1) an algorithm with detailed analysis about oil and gas mature fields and 2) informatics applied to energy efficiency. He has a master degree in computational modeling.

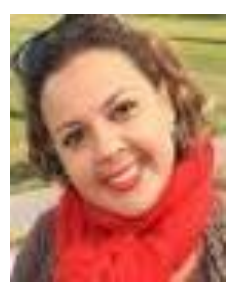

Ana Paula Maia Tanajura is a senior researcher at Senai Innovation Institute for Logistics, a professor at Senai Cimatec Faculty and a PhD candidate in the Industrial Engineering Program at the Federal University of Bahia. Her PhD work deals with the development of a multi-agent model applied to oil field management, in a case study with Petrobras. In 2013, Ana Paula was a PhD guest student in Artificial Intelligence team at Norwegian University of Science and Technology (NTNU). Currently, she also acts as the project leader of a project with the company PetroRecôncavo, the second largest oil \& gas producer in Bahia, Brazil, to develop a system to support decision making process using the multi-agent approach. Ana Paula is a chemical engineer and holds a master degree in business administration, both from UFBA (Federal University of Bahia, Brazil).

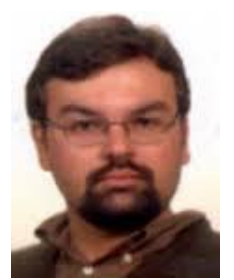

Francisco Gaudencio Mendonça Freires has degree in civil engineering from the Federal University of Ceará, 1996, he holds a master degree of engineering production at the Federal University of Santa Catarina, 2000 and a PhD degree in industrial engineering and management, from the Faculty of Engineering, Porto University, 2007.

He has experience in production engineering with an emphasis in business logistics and operations management, acting on the following topics: supply chain management, reverse logistics, performance evaluation and cost management, operations. He was professor at Federal University the São Francisco Valley (UNIVASF) by 2011 . He researched the issue of logistics and management of the biofuels supply chain and fruit production in semi-arid northeast. Also developed research in the area of logistics intermodal development of the São Francisco River.

Prof. Freires is currently an associate professor, at the Department of Mechanical Engineering of the Polytechnic School of the Federal University of Bahia, UFBA. He also has the postgraduate diploma in industrial engineering program (IEP), Federal University of Bahia, researching when the reactivation of mature oil fields in the perspective of supply chain management.

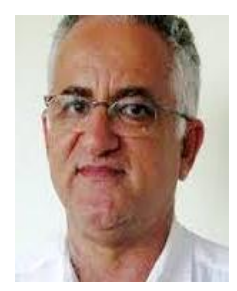

Ednildo Andrade Torres is the coordinator of the Energy and Gas Laboratory (LEN), the Polytechnic School of UFBA with post doctorate degree at FAMU/FSU US, a doctor degree of energy UNICAMP, a MA degree from University of São Paulo, Polytechnic School, graduation at the Federal University Bahia. He was the head of two periods of the Department of Chemical Engineering, UFBA. He has 30 years of experience in the area of technological development between Industrial Research Centers and Universities.

He has more than 10 technology products, and several presentations at national and international conferences. His students won the Technological Awards Environmental Bahia 2004 and Petrobras Gas-Energy Network 2004. In 2006 he won the Innovative Researcher Award of the Year awarded by FAPESB. In 2008 he was the president of the Organizing Committee of the V CONEM - National Congress of Mechanical Engineering, held in Salvador from 25 to 28 August 2008. It has or had agreements with national and international companies such as penetration Braskem, Monsanto, Griffin, Carib Metals, Petrobras, Polythene, Petrobahia, Gas Bahia. He is the coordinator of several $\mathrm{R} \& \mathrm{D}$ projects with financing agencies $\mathrm{CNPq}$, FINEP, FAPESB, Petrobras / ANP.

Prof. Torres is a member of the Bahia Academy of Sciences, is the deputy coordinator of INCT Energy and Environment, based in UFBA. He was the coordinator of Technological Development Area and Entrepreneurship UFBA for 6 years, was the CEO of the Energy Institute and the State of Bahia Environment, had been the coordinator of the Center for Energy and Environment Federal University of Bahia (CIEnAm) for 8 years, coordinated the program graduate and Energy and Environment $(\mathrm{PhD})$ for two periods. Guided 30 students master more than 10 doctoral students and about 100 undergraduates, more than 30 students of expertise. 